\title{
VISUOSPATIAL ANALYSIS OF THE PRINTED WORD
}

\author{
LAURA GLASER \\ Elaine Stevens, Assoc., Waterville, Maine \\ and \\ ANN VANDEMARK \\ The University of Michigan, Ann Arbor, Michigan
}

\begin{abstract}
Aphasic individuals often lose the ability to analyze written information phonetically because of left hemisphere damage experienced through cerebrovascular accident (CVA) or head trauma. In this study, aphasic and normal adults demonstrated use of a right hemisphere visuospatial strategy to analyze printed whole words and word parts such as prefixes and suffixes. The performances of the two groups were similar, suggesting that the hypothesized strategy could be useful as a reading approach for aphasics.
\end{abstract}

Therapy programs, focusing on use of the right hemisphere to assist the damaged left hemisphere, have proved somewhat effective in improving the communication skills of aphasic patients. The teaching of Amerind, an ideographic gestural communication system, has been highly successful in restoring word and phraselength expression (Heilman et al., 1979; Skelly, 1979), as has the use of melodic intonation therapy, a program that employs the rhythmic and musical talents of the right hemisphere (Sparks et al., 1974; Sparks and Holland, 1976). Visual communication systems using geometric and ideographic forms to represent meaningful units have aided these individuals in mastering descriptive skills, comprehension of commands, and word order within phrases (Gardner et al., 1976). Research to date regarding further ways in which the right hemisphere might assist the damaged left hemisphere or assume primary function during communication has been sparse. This article examines the question: Can left brain-damaged aphasic individuals use the presumably intact right hemisphere to facilitate word recognition during a visual reading task?

Although the left hemisphere is traditionally regarded as the center for verbal functions, studies suggest that the right hemisphere is more efficient than the left hemisphere in extracting complex visual features and processing visuospatial information about both verbal and nonverbal material (Berlucchi, 1979; Faglioni et al., 1969; Gardner, 1974; Hellige and Webster, 1979; Kelter et al., 1977; Warrington and James, 1967).

Address correspondence to Laura Glaser, Elaine Stevens Assoc., P.O. Box 362, Waterville, ME 04901 .

(1) Elsevier Science Publishing Company, Inc., 1983

52 Vanderbilt Ave., New York, NY 10017

$0021-9924 / 83 / \$ 03.00$ 
Comprehension of written language normally involves transcoding from the visual to the auditory system (Carmon et al., 1977; Heilman et al., 1979; Kapur and Perl, 1978). This process appears to lateralize at an early stage of reading development to the analytical left hemisphere (Warrington and Shallice, 1980). Kana-Kanji studies suggest, however, that word images can be comprehended without transcoding, by using a right hemisphere visuospatial strategy to extract semantic properties from iconic images, as in a direct graph-meaning association (Sasanuma, 1974; Sasanuma and Itoh, 1976; Yamadori, 1975).

Warrington and Shallice (1980) differentiated between encoding iconic images (ideograms) and visual word forms, or letters comprising ordered familiar units such as syllables, morphemes, or whole words. These workers postulated that ideograms were processed by the right hemisphere and word forms by the analytical left, thereby explaining poor performances by aphasic subjects on word-form reading tasks.

A single-subject study suggests that the right hemisphere is able to process words as complete units (Carmon et al., 1977). The subject, trained to recognize words as whole visual patterns rather than a phonetic integration of letters, learned to read aloud 800 words and 100 phrases. If graphemes were added to or subtracted from the learned stimulus (e.g., addition of $s$ to car), or word order within a phrase was altered, the subject did not recognize the visual pattern. Thus, despite an inability to translate a sequence of graphemes into a sequence of phonemes, the individual was able to process written information pictorially.

Particular word classes and word relationships appear to be easier for the right hemisphere to process. Highly imageable words are most accurately comprehended by split-brain (Hecaen and Albert, 1978) and aphasic subjects (Kapur and Perl, 1978). Word sequences appear to be difficult for the right hemisphere to comprehend (Hecaen and Albert, 1978; Marcie et al., 1965), although some comprehension has been demonstrated (Carmon et al., 1977).

It has thus been shown that the right hemisphere is capable of extracting and storing the shape of a word and matching it to an oral production (Carmon et al., 1977). However, this was a single-subject study and it has not been ascertained that other left brain-damaged individuals are capable of using stimulus shape to facilitate recognition of words. In addition, the subject's response required a verbal production of the word, often a difficult task for aphasics and one that necessarily confounds results when studying reading comprehension. The study implied that only whole words could be recognized by the subject, rather than parts of words. This issue has also been raised by Warrington and Shallice (1980).

This study examines whether aphasic individuals can use the presumably intact right hemisphere to facilitate the processing of single words and word parts by matching outlines of whole words or syllables to one of two printed words. If aphasic individuals demonstrate this ability, it may be possible to devise an approach to reading focusing primarily on the right hemisphere. This would be 
advantageous, as the research has demonstrated that phonetic analysis of written information, a left hemisphere function, is often compromised in aphasic individuals.

\section{Methods}

\section{Subjects}

Fifteen aphasic individuals selected from the University of Michigan Residential Aphasia Clinic served as subjects for the study. They ranged in age from 22 to $67 \mathrm{yr}$, with a mean age of $40.2 \mathrm{yr}$. Four subjects were female, 11 were male. Mean, range, and standard deviation for the overall percentile and for scores on subtests $\mathrm{V}$ and VII on the Porch Index of Communicative Ability (PICA) (Porch, 1967) are reported in Table 1 . Eight of the 15 aphasic subjects had left hemisphere cerebral damage of vascular nature, such as cerebrovascular accident (CVA) or aneurysm. ,Seven subjects had experienced closed head injuries, four with possible right hemisphere damage as well. The site of cerebral lesion, according to medical records, varied widely. At the time of testing, subjects ranged from 7 mo postonset of aphasia to $117 \mathrm{mo}$, with a mean of $39.1 \mathrm{mo}$.

All subjects were right-handed before the CVA or closed head injury. All, except for one subject with an 11th-grade education, had completed high school. Twelve subjects were receiving intensive speech/language therapy at the time of testing. The other three subjects were receiving speech/language therapy of a less intensive nature.

A control group of 15 non-brain-damaged adults was matched to the aphasic group on the basis of age, sex, and education. The group ranged in age from 24 to $71 \mathrm{yr}$, with a mean age of $39.1 \mathrm{yr}$. All the normal subjects had completed at least a high school education and were right-handed.

\section{Materials}

A list of 36 word pairs was compiled. All stimuli were selected from the 6000 most commonly used words in the English language (Eaton, 1940). Items were

TABLE 1

Mean, Range, and Standard Deviation for Overall Percentile and Subtests V and VII on the Porch Index of Communicative Ability*

\begin{tabular}{lllc}
\hline \multicolumn{1}{c}{ Variable } & Mean & \multicolumn{1}{c}{ Range } & Standard Deviation \\
\hline Overall percentile & 66.6 & $35-97$ & 17.7 \\
Subtest V & 12.1 & $7.7-14.8$ & 2.0 \\
Subtest VII & 13.3 & $11.0-15.0$ & 1.5 \\
\hline
\end{tabular}

*For 15 aphasic subjects. 
separated into noun, verb, and adjective classes. If a word could be placed in more than one category (e.g., wanted could be both a verb and an adjective), it was used in its most frequently occurring word class, as specified by Eaton (1940). Words occurring with equal frequency in more than one word class were not included. Each word was used only once. In constructing the word list, three variables were considered: intrapair word length, word class, and syllabification versus whole words.

Intrapair word length was varied in 12 word pairs, with equal numbers of nouns, verbs, and adjectives, one item being four graphemes in length, the other seven. Word length was held constant in all other stimuli, each item being six graphemes in length. This condition was included to ascertain whether recognition of word shape was facilitated by differing word length.

The second variable considered was word class. The stimulus list comprised 12 noun pairs, 12 verb pairs, and 12 adjective pairs. This condition was included in order to determine whether word class facilitated or influenced recognition of word shape.

The third condition compared whole word shapes with word shapes divided into syllables. Twelve word pairs with equal numbers of nouns, verbs, and adjectives were used in this condition.

Itens were selected and paired on the basis of shape difference. Words of similar meaning (e.g., yellow and golden) were not paired together. The stimulus item in each pair to be represented by whole word shape was selected at random. The items represented by syllabic word shape were selected because they included common prefixes, suffixes, and verb tense markers. Words were syllabified according to Stein (1975). Intrapair order was designated randomly, and the entire word list of 36 stimulus pairs was then randomized.

Word pairs and the item matched to the shape were typed side by side in pica type:

$\begin{array}{lll}\text { Item } A & \text { Item } B & \text { Item }(A \text { or } B) \\ \text { star } & \text { nothing }\end{array}$

The designated shape word (on the right) was outlined in black ink, and the graphemes were erased. The word list was then duplicated. The 36 stimulus word pairs and the associated word shapes were presented singly on 4-in.-by-6-in. white index cards. A list of stimulus pairs appears in Appendix A.

\section{Procedures}

Each subject viewed 36 word pairs and associated shapes on individual cards. Stimuli were presented one word pair at a time in a small, quiet, well-lit room, attended only by the examiner. The subject was required to view the two printed 
words and the word shape appearing on the card and to decide which word best corresponded to the shape. The subject was asked to point to the appropriate response. The stimulus cards were presented in the same order every time. Each subject was given the following instructions:

If you could fit one of these two words into this shape, which word would fit the best? Point to it.

A training session using two words pairs not included in the subsequent analysis preceded the actual test in order to ensure that the subjects understood the task. All responses were recorded on answer sheets by the experimenter. Subjects were encouraged not to talk during the task in an effort to minimize auditory interference.

\section{Results}

A univariate one-way ANOVA between the total correct responses of the aphasic group and the total correct responses of the normal group indicated that the scores of the aphasic group were significantly lower than those of the control group ( $F=10.807, d f=1, p=0.01$ ). Aphasic subject scores ranged from 21 to 36 correct, with an average of 4.6 errors on the 36 -item task. Control subject scores ranged from 33 to 36 , with an average of 0.73 errors.

Results of post hoc $t$-tests for independent measures comparing aphasic performance with control performance on each variable (intrapair word length, syllabification, word class) indicated that in every case, aphasics made significantly more errors than controls in matching the printed word to a word shape. $t$ test results appear in Table 2 . It is noteworthy that syllabified items incurred

TABLE 2

$t$-Test Scores for Independent Measures of Aphasic Performance vs. Control Performance on All Stimulus Variables

\begin{tabular}{lccc}
\hline \multicolumn{1}{c}{ Variable } & t-value & $d f$ & $p$ \\
\hline Aphasic group & & & \\
Syllabified vs. nonsyllabified & 2.31 & 28 & 0.05 \\
Noun/verb & 1.31 & 28 & $>0.05$ \\
Noun/adjective & 0.27 & 28 & $>0.05$ \\
Adjective/verb & 0.97 & 28 & $>0.05$ \\
Same length/different length & 2.06 & 28 & 0.05 \\
& & & \\
Normal group & & 28 & 0.05 \\
Syllabified/nonsyllabified & 2.28 & 28 & $>0.05$ \\
Noun/verb & 1.70 & 28 & $>0.05$ \\
Noun/adjective & 0.49 & 28 & $>0.05$ \\
Adjective/verb & 1.47 & 28 & 0.01 \\
Same length/different length & 2.98 & & \\
\hline
\end{tabular}


significantly more errors than did nonsyllabified items among both groups, as did same-length stimulus pairs.

While the aphasic group performed less accurately than did the control group in terms of total number of correct responses, the pattern of errors appeared to be similar between the groups. The Kuder-Richardson Reliability Test for Individual Items indicated that all subjects responded similarly to individual test items $\left(r_{t t}=\right.$ 0.83 , with 0.70 indicating high reliability). Thus, while aphasic subjects made more errors than did control subjects, they made the same kinds of errors.

Correlations were computed between overall test scores for the aphasic group and overall percentile scores for reading subtests V and VII of the Porch Index of Communicative Ability. No significant correlations were indicated (test scoreoverall PICA percentile: $r=0.1798$; test score-PICA V score: $r=0.1232$; test score-PICA VII score: $r=-0.2589$ ).

\section{Discussion}

Aphasic performance on this task was very similar to the normal performance. Although the normal subjects were more successful as a group, some of the aphasic subjects performed the task without error. Using the lowest normal score (33 of 36 correct) as a cutoff, almost one-half the aphasic group responded within the normal score range. This finding suggests that both groups approached the task in the same way and that the hypothesized strategy could be useful as a reading approach.

Three aphasic subjects, one with possible right hemisphere damage caused by a closed head injury, achieved scores below 30 correct. Identifying information and relevant PICA data for these subjects are presented in Table 3. No single obvious factor appears to be responsible for the low scores. A possible explanation is that these individuals may have been struggling between an analytical left and visuospatial right hemisphere approach to the task, and interference from the left hemisphere hindered successful use of the right.

TABLE 3

Relevant Data for the Three Aphasic Subjects with Lowest Scores on the Experimental Task

\begin{tabular}{ccccccc}
\hline $\begin{array}{c}\text { Subject } \\
\text { Number }\end{array}$ & MPO $^{a}$ & Age & Percentile $^{b}$ & $\begin{array}{c}\text { PICA } \\
\text { V }\end{array}$ & $\begin{array}{c}\text { PICA } \\
\text { VII }\end{array}$ & $\begin{array}{c}\text { Right } \\
\text { Hem. }\end{array}$ \\
\hline 3 & 117 & 31 & 55 & 7.7 & 11.8 & Yes \\
4 & 38 & 59 & 43 & 12.8 & 13.7 & No \\
9 & 27 & 20 & 71 & 11.0 & 14.1 & No \\
\hline
\end{tabular}

${ }^{a}$ Signifies months postonset of aphasia.

${ }^{b}$ Signifies overall percentile score on the Porch Index of Communicative Ability.

'Signifies presence of right hemisphere damage, according to medical records. 
While it has been suggested that aphasics are able to perceive only whole-word shapes (Carmon et al., 1977; Warrington and Shallice, 1980), aphasic subjects in the present study demonstrated the ability to associate visually such syllables as prefixes and suffixes with corresponding shapes. Syllabified items incurred the most errors from both groups. It is possible that word shapes in syllabified form may not have been as "recognizable" as whole word shapes. The difficulty experienced by both groups on this particular task may be attributed to a need to shift from right hemisphere spatial analysis in matching whole word shape, to left hemisphere linguistic analysis in ascertaining where to syllabify the specific item.

Word class (noun, verb, adjective) did not affect response in selecting appropriate word shapes, although it had been suggested that highly imageable nouns might be easier to visualize by the right hemisphere (Hecaen and Albert, 1978; Kapur and Perl, 1978). Thus, while ideographic reading and word-shape recognition may both be right hemisphere processes, they are not the same process.

A comparison between stimulus items of same length and those of different length revealed that word pairs of different length were significantly easier to match to the given word shape for both subject groups. This result would be expected if the subjects were using the right hemisphere, as the difference between short and long items is a spatial distinction made by the right hemisphere. It was observed that aphasic responses to different-length items were generally more rapid than responses to same-length items, suggesting a direct right hemisphere approach.

A final comparison, relating overall task performance on the experiment with reading scores and the overall percentile score obtained on the Porch Index of Communicative Ability demonstrated no significant correlation between these measures. This finding supports the theory that the experimental task used a different mechanism (right hemisphere) than that used normally to read (left hemisphere), as subjects who performed well on the PICA reading subtests did not necessarily achieve high scores on the experimental task. In addition, the lack of correlation between scores indicates that overall communicative ability, as denoted by the PICA overall percentile ranking, is unrelated to the aphasic subject's ability to perform on this task. This suggests that those aphasic individuals who are poor communicators, as well as those who achieve a high ranking in communicative ability, may benefit from a reading approach that uses the visuospatial abilities of the right hemisphere.

In summary, the aphasic individual often loses the ability to analyze written information phonetically as a result of left hemisphere damage experienced through head trauma or CVA. However, right hemisphere abilities may successfully assist in extracting information from the printed word. In the present study, 15 aphasic adults demonstrated this ability by accurately matching word shapes to printed words. 


\section{Appendix A}

\section{Stimulus Word List}

\begin{tabular}{|c|c|c|c|}
\hline treaty & doctor & sacred & unable \\
\hline pouring & kill & reflect & urge \\
\hline admire & decide & careful & deep \\
\hline heater & people & eating & follow \\
\hline willing & ugly & ball & teacher \\
\hline village & lady & beckon & vanish \\
\hline forbid & engage & nicest & remote \\
\hline listen & travel & famous & little \\
\hline rich & upright & wanted & excite \\
\hline persist & wait & demand & regret \\
\hline choking & draw & violent & easy \\
\hline basket & thread & feather & foot \\
\hline wallet & forest & shrewd & rugged \\
\hline warmth & tongue & star & nothing \\
\hline golden & vacant & prompt & trusty \\
\hline harbor & shadow & strong & yellow \\
\hline useful & modern & action & system \\
\hline hiver & appear & speech & degree \\
\hline
\end{tabular}

\section{References}

Berlucchi, G. (1979). The role of stimulus discriminability and verbal codability in hemisphere specialization for visuo-spatial tasks. Neuropsychologia. 17(2): 195-202.

Carmon. A., Gordon, H., Benhal, E., and Harness, B.Z. (1977). Retraining in literal alexia: Substitution of a right hemisphere perceptual strategy for impaired left hemispheric processing. Bull. Los Angeles Neurol. Soc. 42(2):41-50.

Eaton, H. (1940). The Word Frequency Dictionary. New York: Dover.

Faglioni, P. Scotti, G., and Spinnler, H. (1969). Impaired recognition of written letters following unilateral hemispheric damage. Cortex. 5:120-133.

Gardner, H. (1974). The naming and recognition of written symbols in aphasic and alexic patients. $J$. Communication Dis. 7:141-153.

Gardner, H., Zurif, E. B., Berry, T., and Baker, E. (1976). Visual Communication in Aphasia. Neuropsychologia. 14:275-292.

Hecaen, H. and Albert, M. L. (1978). Human Neuropsychology. New York: Wiley.

Heilman, K., Rothi, L., Campanella, D., and Wolfson, S. (1979). Wernicke's and global aphasia without alexia. Arch. Neurol. 36:129-133.

Hellige, J. B. and Webster, R. (1979). Right hemisphere superiority for initial stages of letter processing. Neuropsychologia. 17:653-660.

Kapur, N. and Perl, N. T. (1978). Recognition reading in paralexia. Cortex. 14:439-443.

Kelter, S., Cohen, R., Engel, D., List, G, and Strohner, H. (1977). Verbal coding and visual memory in aphasics. Neuropsychologia. 15:51 $\cdots 60$ 
Marcie, P., Hecaen, H., Dubois, J., and Angelergues, R. (1965). Les troubles de la realisation de la parole au cours des lesions de l'hemisphere droit. Neuropsychologia. 3:217-247.

Porch, B. E. (1967). Porch Index of Communicative Ability. Palo Alto: Consulting Psychologist Press.

Sasanuma, S. (1974). Kanji vs. Kana processing in alexia with transient agraphia. Cortex. 10:89-97.

Skelly, M. (1979). Amer-Ind. New York: Elsevier-North Holland.

Sparks, R., Helm, N., and Albert, M. (1974). Aphasia rehabilitation resulting from melodic intonation therapy. Cortex. 10:303-316.

Sparks, R. W. and Holland, A. (1976). Method: Melodic intonation therapy for aphasia. J. Speech Hearing Dis. 41:287-297.

Stein, J. (ed.) (1975). The Random House College Dictionary. New York: Random House.

Warrington, E. and James, M. (1967). Disorders of visual perception in patients with localized cerebral lesions. Neuropsychologia. 5:253-266.

Warrington, E. K. and Shallice, T. (1980). Word form dyslexia. Brain. 103:99-112.

Yamadori, At. (1975). Ideogram reading in alexia. Brain. 98:231-238. 